\title{
Molecular design of a minimal peptide nanoparticle
}

Raja Dey, Yan Xia, Mu-Ping Nieh, and Peter Burkhard

Number of Pages: 5

Number of Figures: 4 


\section{Supplemental Fig. S1}

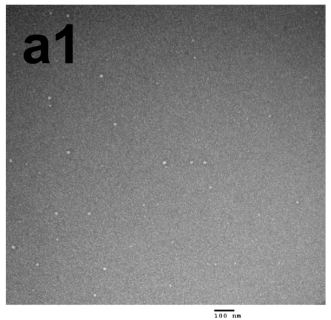

H40, pH 8.5

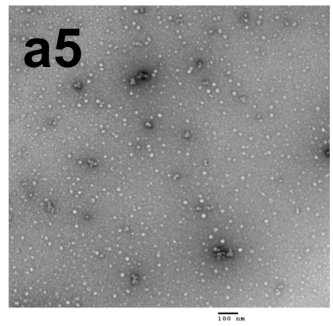

H120, pH 7.0

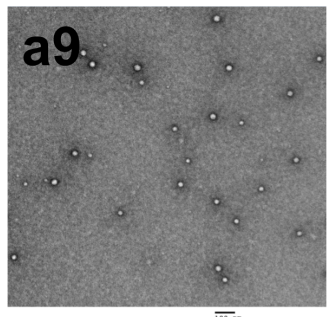

H150, pH 7.0

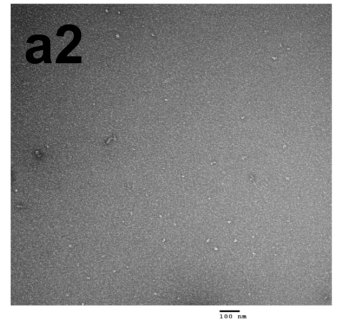

H50, pH 8.5

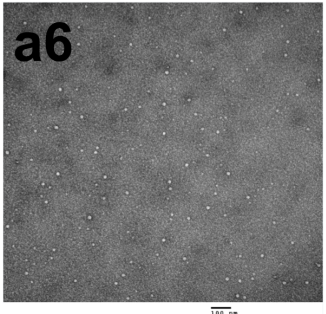

H120, pH 7.5

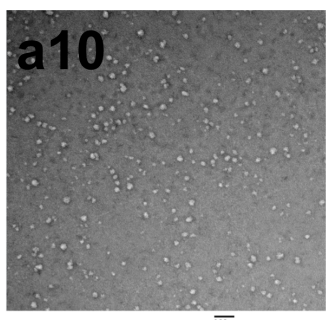

H150, pH 7.5

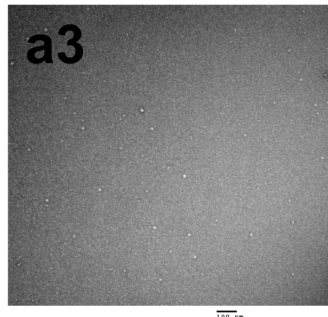

H80, pH 8.5

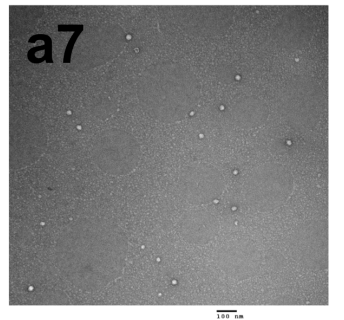

H120, pH 8.0

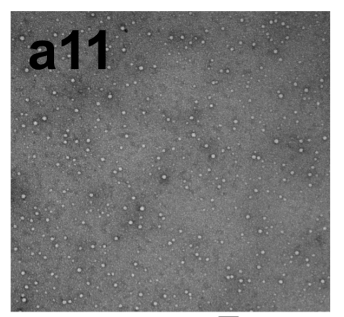

H150, pH 8.0

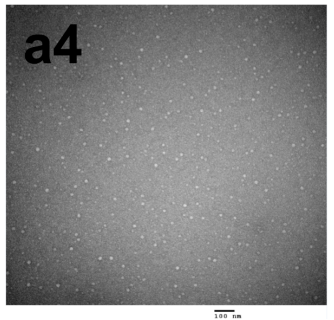

H120, pH 8.5

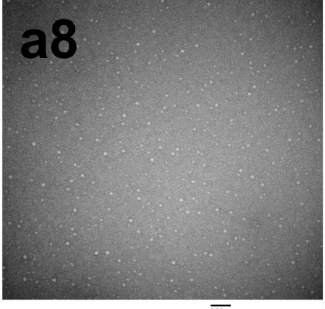

H120, pH 8.5

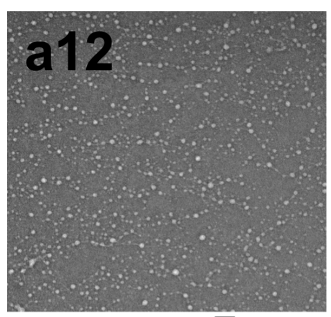

H150, pH 8.5

Supplemental Figure S1. Transmission electron microscopy imaging of peptide $5 \mathrm{~b}$ under different $\mathrm{pH}$ and salt condition. The salt concentration of $\mathrm{NaCl}$ is indicated by e.g. $\mathrm{H} 40$, which means $40 \mathrm{mM} \mathrm{NaCl}$. 


\section{Supplemental Fig. S2}
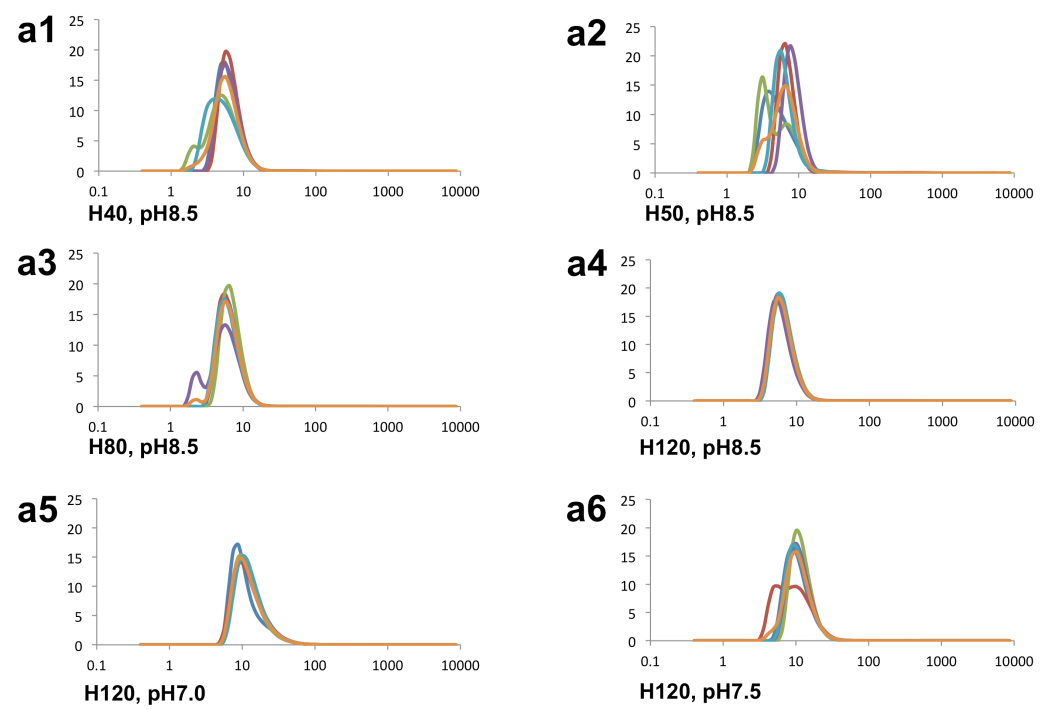

\section{Supplemental Fig. S2}
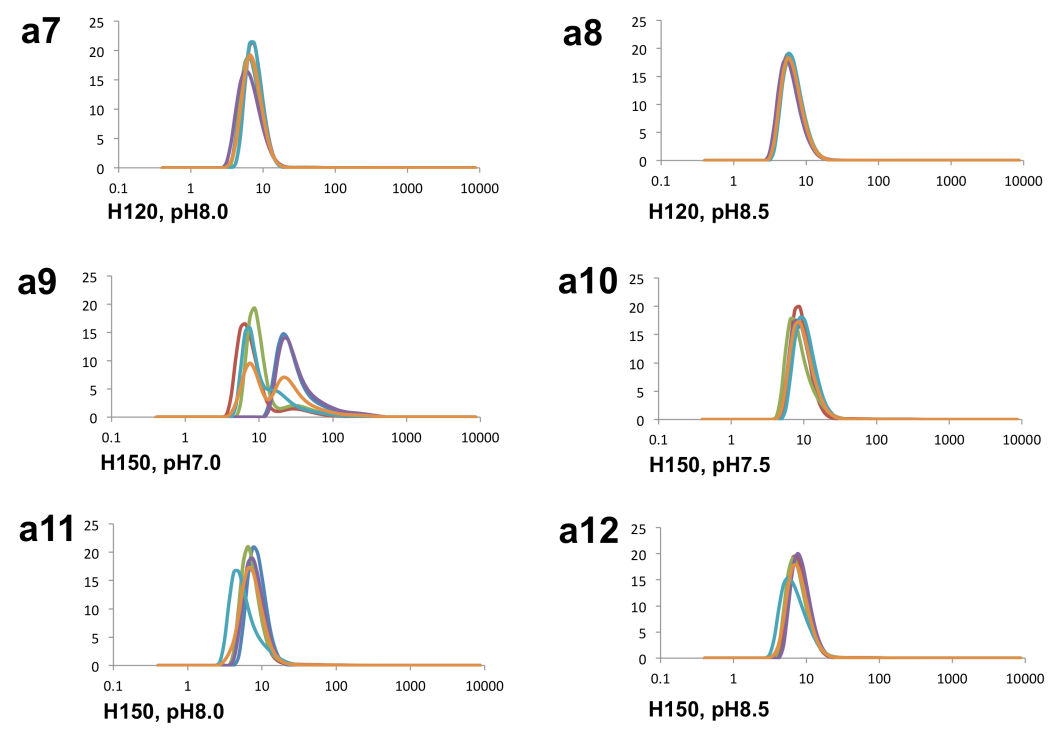

Supplemental Figure S2. A series of DLS studies of peptide $5 \mathrm{~b}$ at different salt and $\mathrm{pH}$ conditions. The salt concentration of $\mathrm{NaCl}$ is indicated by e.g. $\mathrm{H} 40$, which means $40 \mathrm{mM} \mathrm{NaCl}$. 
Fig. S3

a)

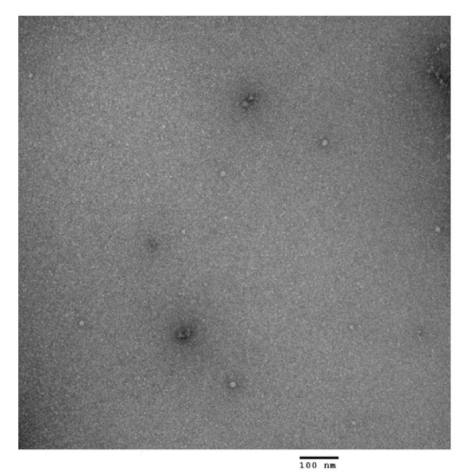

b)

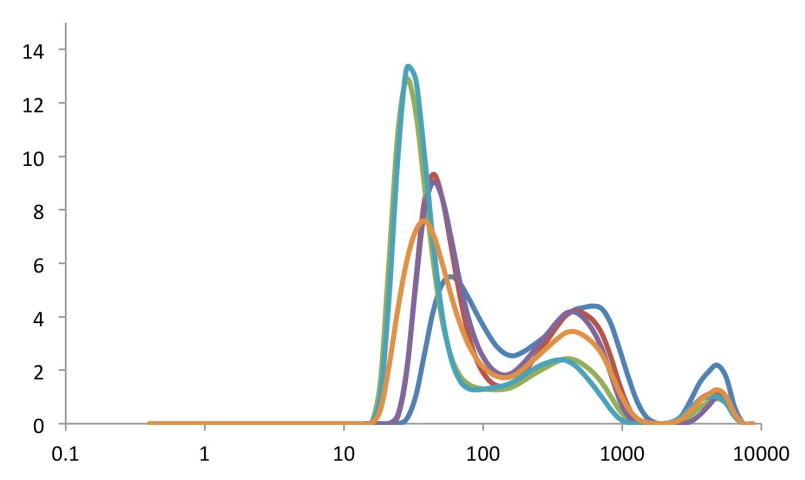

$\mathrm{H} 100, \mathrm{pH} 7.0$

Supplemental Figure S3 presents an electron microscopy image of the unmodified peptide 5 and the corresponding DLS curve under the same near physiological condition $(100 \mathrm{mM} \mathrm{NaCl}$ at $\mathrm{pH}$ 7.0). The EM image in panel a) shows an aggregation and few larger size particles. The dynamic light scattering curve of this peptide in panel b) highlights a mixture of aggregates and larger particles of about $52 \mathrm{~nm}$ in diameter. 


\section{Fig. S4}

a)

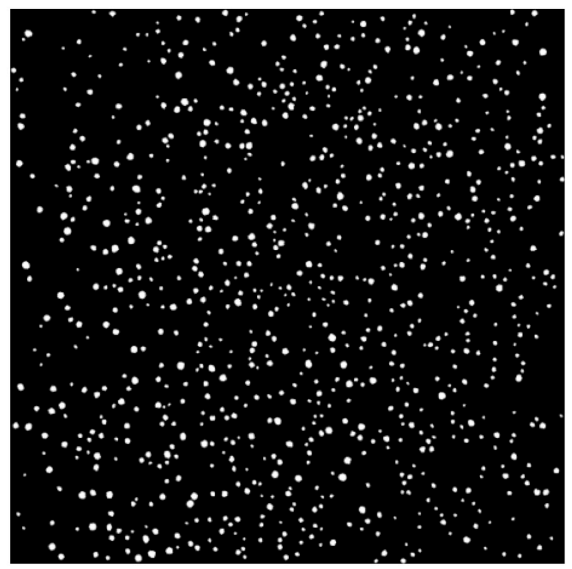

b)

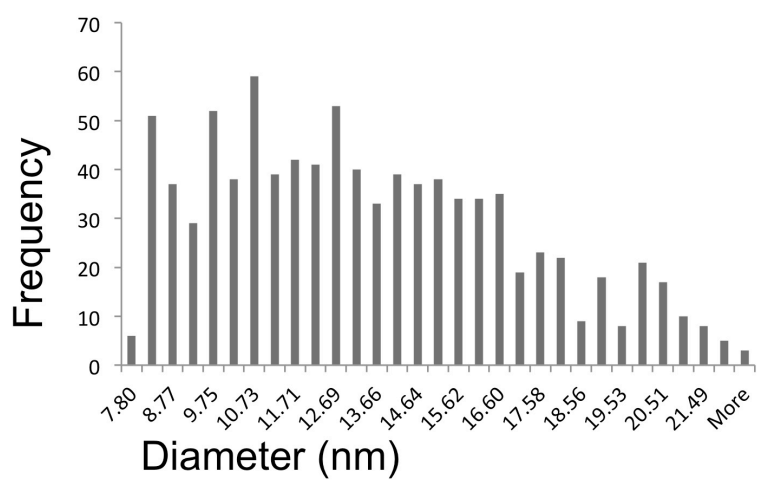

Supplemental Figure S3. Panel a) shows the processed electron microscopy image using Image $J$, and a size distribution histogram of peptide $5 \mathrm{~b}$ under physiological conditions is shown in panel b). The preparation of the histogram was done according to Schneider, C. A. et al (2012), Nature methods 9(7): 671-675, PMID 22930834) 